\title{
A EXPERIÊNCIA DE DOCENTES EM FORMAÇÃO INICIAL COM O ENSINO REMOTO: REFLETINDO SOBRE DESAFIOS EM BUSCA DE SOLUÇÕES PROVÁVEIS
}

\author{
Student Teachers' Experiences with Emergency Remote Teaching: \\ Reflecting on Challenges in Search for Possible Solutions
}

\author{
Marina Cavalcanti Tavares CLEMENTE \\ Programa de Pós-graduação em Linguística Aplicada \\ Universidade Estadual do Ceará \\ marina.clemente@aluno.uece.br \\ https://orcid.org/0000-0001-5503-533X \\ Glenda Demes da CRUZ \\ Universidade Estadual do Ceará \\ glenda.demes@uece.br \\ https://orcid.org/0000-0001-7600-2596
}

RESUMO: O ano de 2020 trouxe consigo uma transformação na realidade mundial. A chegada de uma pandemia modificou a maneira de viver de todas as pessoas. Na área da educação, a maioria dos profissionais, sem uma preparação ou formação prévia, precisou se reinventar, fazendo uso das mais diversas tecnologias para seguir trabalhando. $\mathrm{O}$ cenário pandêmico na educação evidenciou lacunas na formação tecnológica de grande parte dos professores, o que nos motivou a refletir sobre a situação daqueles que se encontram neste momento em formação inicial docente. Com o propósito de conhecer as dificuldades enfrentadas pelos professores em formação inicial com o ensino remoto e propor sugestões ancoradas na literatura existente para mitigar/superar alguns dos desafios apresentados, contamos com um corpus composto por 20 relatos de experiência com o ensino remoto emergencial, escritos por alunos das disciplinas de Estágio Supervisionado em Língua Inglesa da Universidade Estadual do Ceará (UECE). A presente pesquisa busca, por meio da análise dos relatos destes sujeitos, investigar como os alunos estagiários têm vivenciado o ensino remoto, quais desafios têm sido enfrentados, bem como propor sugestões, a partir de publicações existentes, de práticas que podem auxiliar a superar/mitigar tais desafios. PALAVRAS-CHAVE: Formação inicial; Ensino remoto; Desafios; Propostas.

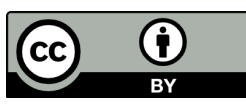




\begin{abstract}
The year 2020 transformed the reality around the world. The arrival of a pandemic has changed everyone's way of life. In education, most professionals needed to reinvent themselves in order to use the most diverse technologies to continue working and that was done without prior preparation or training. The pandemic scenario in education showed gaps in the technological training of most teachers. With that in mind, we felt motivated to discuss the situation of those who are currently in teacher development. In order to understand the difficulties faced with emergency remote teaching by student teachers and to propose suggestions anchored in the existing literature to mitigate / overcome some of the challenges presented, we analyzed 20 reports written by undergraduate student teachers taking a degree in English language teaching at the State University of Ceará (UECE). The reports described their experiences with emergency remote teaching. In order to propose solutions for the challenges they have experienced with remote education, we identified the most frequent challenges mentioned in their writings and, based on existing publications, we suggested practices that can help overcome / mitigate such challenges. KEYWORDS: Teacher development; Emergency remote teaching; Challenges; Solutions.
\end{abstract}

\title{
INTRODUÇÃO
}

O ano de 2020 trouxe consigo uma transformação na realidade mundial. A chegada de uma pandemia modificou a maneira de viver de todas as pessoas, em todos os aspectos que envolvem o ser humano (saúde, educação, moradia, trabalho, relações sociais etc.). Fomos "convidados" a nos (re)descobrir e a (re)aprender a fazer muito do que já estávamos acostumados a fazer de determinadas maneiras. Abruptamente, muitos ficaram confinados em suas casas, e suas atividades mudaram de presenciais para remotas.

$\mathrm{Na}$ área da educação, a maioria dos profissionais, sem uma preparação ou formação prévia, precisou se reinventar e começar a utilizar as mais diversas tecnologias para seguir trabalhando. Os alunos e as suas famílias também tiveram que "correr atrás" para conseguirem acompanhar as aulas e as atividades.

Tal situação apresentou de maneira clara e patente uma ausência na formação de grande parte dos professores: apesar do ensino a distância e do ensino remoto já existirem e serem uma realidade, não há uma preparação/formação para se trabalhar com eles. Muitos de nós nunca havíamos tido contato com tal tipo de ensino antes da Covid-19 e nunca tínhamos precisado lidar com plataformas como Google Meet, Zoom, Microsoft Teams e outras. 
Tais fatos nos conduziram, então, a refletir sobre a situação daqueles que se encontram neste momento em formação inicial docente. A presente pesquisa busca, por meio da coleta de dados com os próprios sujeitos que se encontram em tal realidade, investigar como esses professores em formação têm vivenciado o ensino remoto, quais desafios têm sido enfrentados e propor sugestões, a partir de publicações existentes, de práticas que podem auxiliar a mitigar tais desafios. Para tanto, tratamos da atividade docente na formação inicial de professores; dos desafios do ensino remoto na formação inicial; do contexto da pesquisa; e, partindo de pesquisas existentes, propomos sugestões do que pode ser realizado de modo a diminuir esses obstáculos.

Não buscamos aqui encerrar o assunto, mas trazer uma oportunidade de análise do que os alunos em formação têm vivido neste tempo para, a partir daí, encontrarmos soluções que partam das dificuldades compartilhadas por eles.

\title{
A ATIVIDADE DOCENTE NA FORMAÇÃO INICIAL DE PROFESSORES
}

\begin{abstract}
Para os iniciantes, as incertezas e inseguranças são ainda constantes na sua prática. Para o formador, a preocupação e o compromisso de levar $\mathrm{o}$ formando à aprendizagem e à realização de uma prática concreta $\mathrm{e}$ eficaz. (MORAES; MAGALHÃES, 2017, p. 106)
\end{abstract}

A formação de professores, objeto de estudo de pesquisadores desde o início do século XIX (GATTI et al., 2019), vem sendo amplamente discutida não somente pelos profissionais da educação, como também pelos profissionais da Linguística Aplicada. O trabalho pedagógico, considerado por Gatti et al. (2019, p. 19) como a "[...] essência das atividades escolares e, portanto, a essência do trabalho dos professores", precisa ser aprendido, experimentado, vivenciado, pensado, desenvolvido, uma vez que a dicotomia entre teoria e prática vivenciada na formação inicial, representada pela racionalidade técnica, não garante o sucesso profissional.

É importante que se preze pelo constante desenvolvimento da formação no ensino superior, por meio da partilha de saberes e trocas de experiências do coletivo em atividades de formação. Para Gimenez (2018), os cursos de Letras têm a responsabilidade de centrar a formação não somente nas competências linguístico-comunicativas, mas também em uma relação estreita entre as experiências vividas e as crenças que se desenvolvem a partir delas. Segundo a autora, 
a formação profissional trabalha com a possibilidade de renovação, inovação, de ousadia. A força impactante da socialização nos bancos escolares sobre as identidades de futuros professores precisa ser compreendida nos programas de formação profissional, sob pena de não desafiarmos as práticas que se repetem porque as condições para sua existência permanecem as mesmas, embora os indivíduos sejam diferentes. (ibid, p. 52)

Os saberes relacionados à docência não são inatos, por mais que alguns apostem em talento, vocação ou no fato de que quem sabe executar, sabe ensinar. Segundo Lacerda (2005, p. 90), "[...] No diálogo com os sujeitos, o saber crítico norteia o objeto de trabalho do professor, recriando sua prática profissional". A autora reforça a relevância da compreensão da docência como trabalho, para que haja uma prática interativa e situada no contexto da profissão. Magalhães (2004, p. 61) propõe um repensar do currículo sobre o trabalho dos professores dentro e fora da sala de aula, indivisivelmente relacionado

à compreensão da linguagem na formação de um profissional capaz de descrever, analisar e interpretar sua própria prática, o que lhe propiciará um espaço para a desconstrução de ações rotineiras e possibilidade de reconstruí-las.

Para tanto, propõe um olhar reflexivo para a formação docente, seja ela inicial ou continuada.

A ideia é que sejamos tocados pelas maneiras de fazer e de falar sobre como fazemos, "[...] pensando-as diferentemente e para além da maneira habitual como pensavam antes sobre essas questões" (BRANDÃO, 2016, p. 132). Entendemos como fundamental falar não apenas sobre o que funciona ou não funciona, mas também sobre "[...] os caminhos tomados para realizar o que tem que ser realizado, apesar dos obstáculos" (ibid, p. 137).

\section{OS DESAFIOS DO ENSINO REMOTO NA FORMAÇÃO INICIAL}

Como foi dito na introdução, o ensino a distância e o ensino remoto já existiam antes da pandemia, inclusive há muitos cursos de graduação e pós-graduação realizados a distância em nosso país. Ainda assim, essa não é a realidade de ensino da maioria dos professores, especialmente dos que trabalham na educação básica. Contudo, com a chegada da pandemia, os locais que trabalhavam com ensino presencial precisaram 
migrar para esses outros formatos, muitos dando preferência ao ensino remoto. Coscarelli (2020, p. 15) trata dessa questão ao dizer:

[...] Chamamos ensino remoto e não educação a distância (EaD), porque é uma ação emergencial, são cursos presenciais, que, devido aos impedimentos impostos pela fácil disseminação do coronavírus, impedem os estabelecimentos de ensino de manterem suas atividades presenciais. $\mathrm{O}$ ensino remoto precisou ser feito sem planejamento prévio, sem um ambiente virtual de aprendizagem escolhido com cautela, sem que os professores tivessem tempo de se preparar, de produzir e selecionar materiais e estratégias de ensino adequadas para atividades online. [...] Não se faz $\mathrm{EaD}$ de qualidade de uma hora para outra.

Posto que, no presente artigo, focamos exatamente na realidade gerada pela pandemia, falaremos de forma mais específica do ensino remoto, mas, quando tratamos sobre a formação dos professores, o fato é que estes não se sentem formados para nenhum dos dois formatos.

Uma pesquisa realizada pelo Instituto Península, intitulada "Sentimento e percepção dos professores brasileiros nos diferentes estágios do coronavírus no Brasil", que busca "[...] entender e captar a percepção acerca deste momento atípico e as reflexões sobre a prática docente que surgem a partir dessa nova vivência" (INSTITUTO PENÍNSULA, 2020), apresentou o seguinte resultado em sua segunda etapa de desenvolvimento: "mesmo após seis semanas de isolamento social, $83 \%$ dos professores brasileiros, em média, ainda se sentem nada ou pouco preparados para o ensino remoto, que virou rotina em diferentes pontos do Brasil" e " $88 \%$ dos professores indicaram que nunca tinham dado aula remota antes da pandemia", tal investigação foi "realizada com 7.734 mil professores de todo o país entre os dias 13 de abril e 14 de maio de 2020."

A partir de tais resultados, percebemos esse sentimento dos professores de despreparo, inclusive por nunca terem tido uma experiência como essa antes. Se os professores que estavam em sala de aula se sentiram despreparados, não poderíamos deixar de pensar naqueles que se encontram em formação inicial. O que observamos em relação a esses dois grupos, de professores que já passaram pela graduação e o daqueles que ainda se encontram nela, é que há uma ausência de formação nesse sentido em seu currículo, é como se, até agora, poucos formadores houvessem pensado nesse formato de ensino para a vida profissional.

Vale ressaltar que Almeida (2010, p. 73), ao tratar sobre a formação de professores para a $\mathrm{EaD}$, já dizia que 
Essa formação não é simples, especialmente quando se trata de formação contínua de professores voltada para sua atuação em novos espaços, tempos e culturas, como é o caso da formação on-line integrada com a atuação na EAD on-line, a qual tem como norte as mudanças nas concepções, nos valores, nas crenças e nas práticas, que permitem ao formando mergulhar na nova cultura, reestruturar o pensamento de acordo com os novos modos de expressá-lo, interagir, construir conhecimento, trabalhar em colaboração e reorganizar o próprio tempo.

Apesar de a autora se referir especificamente ao caso da formação na $\mathrm{EaD}$ on-line, podemos transpor tal fala para a realidade do ensino remoto, pois esta formação realmente exige uma reestruturação do profissional, novas aprendizagens; uma verdadeira transformação.

A situação pandêmica criou a necessidade de uma formação de "última hora", a qual foi fornecida por algumas instituições aos seus professores, mas vale ressaltar que muitos passaram pela formação ao mesmo tempo em que já estavam dando suas aulas online, o que dificulta o processo de adaptação ao novo. É interessante que os professores sejam formados para que se sintam seguros em realizar sua atividade profissional.

Jesus (2007) realizou uma análise do discurso de docentes de inglês que fizeram parte de um curso de formação a distância em ambiente on-line, observando indícios de processo de reculturação, reestruturação e reorganização temporal. Em sua observação, ela percebe que "[...] no discurso dos discentes, há uma fase inicial com obstáculos, e uma posterior mais aprazível" (JESUS, 2007, p. 176), ou seja, antes da formação, os professores-alunos demonstravam medo e preocupação, mas, depois da formação, eles falavam da situação utilizando palavras como “conhecimento, agradável e útil”. Portanto, podemos perceber que a presença da formação traz um novo olhar do professor-aluno para a situação.

Dentro dessa perspectiva de adaptação ao on-line, uma outra questão que não pode ser esquecida é a importância da humanização das relações. A distância, a ausência do "olho no olho", o estar em frente ao computador ao invés de fisicamente em frente a sala de aula não devem ser motivos para que os docentes se esqueçam de que as aulas continuam ocorrendo com os alunos; a máquina apenas medeia, mas cabe aos envolvidos no processo de ensino e aprendizagem uma participação ativa. Manter tal questão em mente é necessário para se buscar a manutenção da interação professor-aluno nesse novo modelo de sala de aula. 


\section{CONTEXTO DA PESQUISA}

Araújo (2018, p. 74) considera quatro etapas na formação docente:

[...] a experiência com o ensino antes de uma preparação formal; a formação em uma instituição especializada ou formação inicial; a vivência nos primeiros anos como profissional; e a formação continuada ao longo da carreira.

Aos alunos dos cursos de licenciatura em Letras (licenciatura em Língua Inglesa) da Universidade Estadual do Ceará (doravante, UECE), futuros professores, são oportunizadas duas dessas quatro etapas, por meio das atividades propostas pelas disciplinas ofertadas ao longo do curso, mas é nas disciplinas de Estágio Supervisionado que é proposta ao licenciando a vivência com sua futura profissão no ambiente de trabalho.

O contato com sua futura atividade se dá através de atividades de observação (Estágio Supervisionado I e III em Língua Inglesa) e regência (Estágio Supervisionado II e IV em Língua Inglesa), que têm como objetivo oportunizar a vivência do exercício profissional da docência em seus vários contextos de ensino-aprendizagem. As disciplinas discutem aspectos teórico-metodológicos, bem como sua aplicação à prática em contextos envolvendo o ensino na Educação Básica (Estágio Supervisionado I e II) e em Cursos Livres de Idiomas (Estágio Supervisionado III e IV).

Os desafios impostos cotidianamente pela atividade docente atualmente nos acrescentam mais um: o ensino remoto emergencial que, ao se multiplicar em vários outros desafios, nos impõe um novo olhar sobre o processo de ensino-aprendizagem. O direcionamento deste novo olhar para a prática docente e os desafios que permeiam as vivências de professores em formação inicial com esta nova modalidade de ensino motivaram a presente pesquisa, que conta com um corpus de 20 relatos de experiência produzidos pelos discentes em formação inicial do curso de Letras (licenciatura em 
Língua Inglesa) da UECE $^{1}$ : 12 escritos pelos alunos da disciplina de Estágio III e 8 pelos alunos da disciplina de Estágio IV. Além de tais relatos, o corpus também conta com um questionário sobre as rotinas de trabalho e estudos dos informantes. Ressaltamos que todos os procedimentos realizados para a coleta dos dados seguiram as orientações para procedimentos em pesquisa do Ofício Circular no. 2/2021/CONEP/SECNS/MS.

Diante da imposição de uma reformulação das atividades de estágio devido à pandemia, a formadora das disciplinas de Estágio Supervisionado III e IV propôs aos discentes um questionário com questões relacionadas às suas rotinas atuais de trabalho, de estudos, bem como questões relacionadas ao acesso às tecnologias digitais. As respostas a uma das perguntas constantes do questionário foram utilizadas na tentativa de traçar um perfil dos discentes para uma leitura mais informada dos relatos. O quadro abaixo representa o perfil dos discentes quanto ao contato com o ensino remoto:

Quadro 1: Perfil dos discentes quanto ao contato com o ensino remoto.

\begin{tabular}{|c|c|c|}
\hline Você tem alguma experiência com o ensino remoto? & Estágio III & Estágio IV \\
\hline Bastante & $0 \%$ & $33,3 \%$ \\
\hline Suficiente para ministrar aulas remotamente & $16,6 \%$ & $44,4 \%$ \\
\hline Tenho experiência como aluno, mas não como professor & $58,3 \%$ & $22,2 \%$ \\
\hline Não tenho experiência nem como aluno, nem como professor & $25 \%$ & $0 \%$ \\
\hline
\end{tabular}

Fonte: Quadro desenvolvido pelas autoras - acervo próprio (2020).

Quando indagados sobre sua experiência prévia com o ensino remoto emergencial, 58,3\% dos discentes da disciplina de Estágio III disseram ter experiência apenas como alunos; $16,6 \%$ dos alunos disse ter experiência suficiente para ministrar aulas remotas

\footnotetext{
1 Por conta da realidade pandêmica e dos decretos estaduais de lockdown, paralisando temporariamente as atividades acadêmicas e impossibilitando, portanto, o contato presencial, os questionários foram realizados por meio do Google Forms (formulário do Google), e todos os participantes, antes de preencher o questionário, precisavam responder uma pergunta obrigatória na qual informavam se autorizavam a utilização de seus relatos de experiência, desde que preservado o anonimato, para a realização de futuras pesquisas. Vide modelo dessa parte do questionário na seção Anexos. Ressaltamos que asseguramos a privacidade e o sigilo das informações dos sujeitos e que todos consentiram em participar. Tendo em vista as questões já mencionadas sobre o cenário pandêmico e a janela temporal a qual tínhamos para a realização desta pesquisa, esta não foi submetida ao Comitê de Ética. Assumimos total responsabilidade por todos os dados apresentados neste estudo, conforme as orientações para procedimentos em pesquisa do Ofício Circular no. 2/2021/CONEP/SECNS/MS.
} 
e $25 \%$ alegaram não ter experiência nem como aluno, nem como professor. Não poderíamos deixar de observar que, na turma de estágio III, nenhum discente considerou ter bastante experiência com o ensino remoto.

Quanto aos discentes da disciplina de Estágio IV, 33,3\% disseram ter bastante experiência com o ensino remoto; 44,4 \% disseram ter experiência suficiente para ministrar aulas remotamente; $22,2 \%$ disseram ter experiência como aluno, mas não como professor; e nenhum aluno reportou não ter experiência nem como aluno, nem como professor.

Vê-se, portanto, que o perfil das duas turmas é distinto. Enquanto nenhum aluno considera ter bastante experiência com o ensino remoto na disciplina de Estágio Supervisionado III, nenhum aluno da disciplina de Estágio Supervisionado IV se considera totalmente inexperiente quanto ao ensino remoto.

Observa-se também que, apesar de terem sido realizadas atividades práticas remotas no final do semestre anterior nas disciplinas de Estágio Supervisionado II e III em Língua Inglesa (disciplinas que antecedem as cursadas no semestre atual), nem todos os alunos consideraram sua atividade de estágio como docência. Como o objetivo desta pesquisa é compreender as dificuldades enfrentadas durante o ensino remoto, foram selecionados apenas os textos que relatam as experiências com a atividade docente durante a pandemia. Portanto, dos 20 relatos constantes do corpus desta pesquisa, foram selecionados 11: 4 dos discentes da disciplina de Estágio III e 7 dos discentes da disciplina de Estágio IV.

Com o propósito de conhecer as dificuldades enfrentadas pelos professores em formação inicial com o ensino remoto e propor sugestões ancoradas na literatura existente para mitigar/superar alguns dos desafios apresentados, buscamos responder às seguintes questões: Quais dificuldades os professores na formação inicial enfrenta(ra)m com o ensino remoto emergencial? Que sugestões traz a literatura sobre formação docente para mitigar /superar os desafios encontrados pelos professores na formação inicial?

Para responder às questões acima, contamos com quatro etapas: consulta ao corpus composto por 20 relatos de experiência com o ensino remoto emergencial (alunos das disciplinas de Estágio Supervisionado III e IV em Língua Inglesa); escolha dos relatos apenas dos alunos-estagiários que tiveram experiência com o ensino remoto emergencial como docentes; análise dos relatos (busca pelos desafios mais frequentes na atividade dos sujeitos); busca de sugestões para a mitigação/superação dos desafios na literatura sobre formação docente. 


\title{
REFLETINDO SOBRE DESAFIOS EM BUSCA DE SOLUÇÕES PROVÁVEIS
}

\begin{abstract}
Se por um lado os primeiros anos na profissão são marcados por medos e inseguranças, por outro, eles podem constituir um intenso período de aprendizagem e de desenvolvimento, pois é nessa etapa que o iniciante enfrenta as prescrições do métier, que exigem uma postura responsiva diante das problemáticas e das questões da profissão. Contudo, essas respostas só podem ser adquiridas por meio das experiências vividas e a partir de um processo de desenvolvimento (do) profissional, que consiste em adquirir para si as "senhas" da profissão (MORAES; LOPES, 2019, p. 119).
\end{abstract}

Após uma leitura mais aprofundada dos relatos constantes do corpus, observamos 5 desafios frequentes e imbricados: (falta de) formação adequada e suas implicações; insegurança; manutenção da interação e participação dos alunos; necessidade de dinamismo nas aulas (de educação infantil); e esgotamento. Buscamos estudos que nos embasassem para a sugestão de possíveis formas de mitigar tais desafios, tomando como motivadores os excertos dos relatos que compõem o corpus da pesquisa. Dividimos nossas considerações em subseções, compostas pelo desafio emergente e sugestões de enfrentamento encontradas na literatura sobre formação docente.

\section{(Falta de) formação adequada e suas implicações}

Quadro 2: Excerto de relatos dos participantes

"Precisei lançar mão de uma habilidade que não domino, porém, que comecei a conhecer melhor ao longo do período de isolamento." (Estágio III, relato 4)

"Ensinar de maneira remota, sem preparo, sem avisos ou treinamentos, em um país que não valoriza nem um pouco a educação não é tarefa fácil, não sei nem se um dia ficará." (Estágio IV, relato 8)

Fonte: Acervo das autoras (2020).

O que percebemos a partir dos excertos acima é a indicação da falta de uma formação adequada para o enfrentamento das dificuldades impostas pelo ensino remoto, que nos obrigaram a lidar com o inesperado. O que parecia ser um plano distante chegou a uma velocidade avassaladora, não deixando sequer tempo para pensar e planejar o quê 
e como fazer. Medos e inseguranças comuns à prática docente do professor em formação inicial tornaram-se comuns ao coletivo, afetando formadores, professores experientes, professores iniciantes e professores em formação.

Apesar da evidente falta de uma formação adequada, escancarada pela pandemia, não é de hoje que se discute a questão do letramento digital na formação inicial. Freitas (2010, p. 345) defende a aproximação com o letramento digital não a partir de determinada disciplina, mas "por meio de um trabalho contínuo, no interior de todas as disciplinas nas quais o professor, em sua formação inicial, possa experienciar o letramento digital no próprio processo pedagógico."

Gimenez (2005), ao discutir sete desafios da formação de professores no campo da Linguística Aplicada², traz uma necessidade discutida por muitos, mas ainda tímida na formação inicial e continuada: a construção de comunidades de aprendizagem "na qual os agentes possam ter espaço para discutir dialogicamente e analisar criticamente as razões para suas ações e que direções gostariam de tomar." (p. 198)

$\mathrm{Na}$ tentativa de sanar as lacunas evidentes na formação inicial, iniciou-se, a partir da necessidade do ensino remoto, o movimento de troca de ideias com o coletivo em busca de conhecimento sobre este novo modelo educacional ainda em adaptação. Se por um lado havia a insegurança, falta de treinamento adequado, por outro se viam inúmeras oportunidades síncronas e assíncronas de acesso a diferentes experiências, em contextos diversos.

Assim como o espaço para o diálogo com comunidades de prática, a pesquisa se coloca como fundamental para a tomada de decisões e direções a seguir. Publicações nacionais e internacionais também nos propiciam oportunidades de partilha de experiências vivenciadas em diferentes contextos de ensino-aprendizagem. Trazemos aqui a experiência de Tran $(2020)^{3}$, que se antecipou ao decreto de isolamento social em seu estado. Na semana anterior ao decreto, os professores e alunos de um programa coordenado pelo autor foram instruídos e treinados para o uso do AVA a ser utilizado e foram acompanhados durante todo o processo, contando com feedback frequente dos colegas e da gestão.

\footnotetext{
${ }^{2}$ 1. Definição da base de conhecimento profissional; 2. Relevância das pesquisas para a formação de professores; 3. Abordagem articuladora teoria/prática; 4. Impacto e sustentabilidade das propostas resultantes das pesquisas; 5 . Relação das pesquisas com políticas públicas e formação de professores; 6. Identidade profissional aos formadores; 7. Integração das formações inicial e continuada.

${ }^{3}$ Coordenador de um curso intensivo de língua inglesa da Universidade de Ciência e Tecnologia, em Missouri.
}

Revista X, v. 16, n. 3, p. 703-727, 2021. 
Reflexão e troca com o coletivo são suportes poderosos para o crescimento profissional. A partir do momento em que observamos, refletimos e partilhamos, descobrimos que grande parte de nosso aprendizado não se resume a uma forma de ensinar ou ao método escolhido, mas também no que nos valemos para a busca do conhecimento.

\section{Insegurança}

Quadro 3: Excerto de relatos dos participantes.

"De certa forma, eu estava exercendo o trabalho em casa, no conforto, mas me sentia inseguro, por vários motivos como a conexão da internet, que era o meu maior medo, a internet cair e não conseguir voltar a aula e acabar prejudicando a mim e aos alunos e por não conseguir ter a mesma relação com os alunos online, já que precisa ter uma interação" (Estágio III, relato 12)

"Sei perfeitamente que não havia outra solução, mas como o professor foi inserido nesse universo, para mim, foi um tanto irresponsável e injusto. Primeiro, não houve nenhum treinamento de uso de novas ferramentas, sendo que até hoje, me sinto inseguro para uso de determinadas tecnologias e plataformas; não houve, por parte das instituições preocupação com o equipamento utilizado pelo professor e disponibilidade de serviços de internet, pelo contrário, o que houve foi muita cobrança por parte das instituições que o professor tivesse equipamentos e uma boa conexão de internet." (Estágio IV, relato 6).

Fonte: Acervo das autoras (2020).

Os relatos apresentados acima fazem referência à insegurança relacionada a três questões: o primeiro retrata a questão quanto à conexão com a internet e à conexão com os alunos; já o segundo aborda a insegurança ligada à falta de formação, abordada no tópico anterior. Trataremos, então, a seguir dessa insegurança que pode habitar o professor e pode ser motivada por diferentes situações.

Dentro da conjuntura do ensino remoto, o uso da internet tornou-se imprescindível. Dessa forma, o sistema passou a exigir dos professores uma conexão de qualidade e um maquinário adequado (computador, câmera para filmagem de aulas etc.), sem fornecer meios suplementares para que isso acontecesse. De acordo com Junqueira (2020, p. 35)

A pesquisa TIC Domicílios 2018, conduzida pelo Comitê Gestor da Internet, indicou que, apesar de 93\% dos domicílios contarem com um telefone celular, apenas $19 \%$ possuíam computador de mesa e somente $27 \%$ dos domicílios possuíam computador portátil, sendo, na maioria 
dos casos, apenas um equipamento por domicílio. O estudo revelou também que apenas 39\% dos domicílios possuíam computador e conexão à internet, sendo que quase um terço dessas famílias utilizavam a internet através da conexão instável de chips do tipo 3G ou 4G.

É importante ressaltar que não apenas os alunos se encontram inseridos em tais números, mas os professores também, por isso é normal que eles se sintam inseguros em relação ao uso de sua internet para a realização de sua prática profissional. Percebemos, inclusive, nesse excerto do relato do professor estagiário do Estágio III, uma preocupação própria do docente, o qual não foca sua inquietação apenas em si, mas no fato de que o seu insucesso em sua conexão geraria consequências negativas também para o aluno.

Para além das políticas públicas que possibilitem um acesso melhor e mais igualitário a todos e da ação das escolas privadas que também precisam fornecer condições de trabalho aos seus docentes (o que seria ideal), foi e é necessário se pensar a curto prazo, (re)pensar o conceito de "aula" dentro da realidade e das condições disponíveis (BUNZEN, 2020). Na perspectiva da busca por mitigar a insegurança em tal questão, uma proposta seria a escola, juntamente com todos os profissionais envolvidos no processo educativo, refletir sobre as reais possibilidades de sua ação e o contexto de seus professores e alunos. Como diz Bunzen (2020, p. 24-25)

Se pensarmos em uma pedagogia dos vínculos, cada escola poderia usar diferentes mídias e tecnologias para produzir coletivamente, discutir e refletir na escola sobre diferentes temáticas e questões. [...] A palavra "aula" e seus significados se ampliam consideravelmente com as atividades assíncronas e síncronas. "Aula" passa a ser um conjunto de eventos e atividades de que a turma participa ao longo de um período de tempo, podendo ser em diferentes espaços digitais e plataformas.

A variedade de possibilidades de atuação do contexto aula traria uma gama maior de oportunidades para a atuação profissional do docente e talvez lhe trouxesse mais segurança em tal atuação.

Um outro ponto de insegurança indicado no relato 12, do Estágio III, foi quanto a "conseguir ter a mesma relação com os alunos online, já que precisa ter uma interação", uma vez que a questão da manutenção da interação com os alunos foi apontada como um desafio por outros estagiários, tal assunto abordaremos na subseção seguinte. 


\section{Manutenção da interação e da participação dos alunos}

Quadro 4: Excerto de relatos dos participantes.

"Muitos alunos não participavam por diversas razões: não saber manusear o Teams, ter vergonha de falar ao microfone ou ligar a câmera, não ter um computador ou outro recurso em casa que os possibilitasse assistir as aulas, entre outros." (Estágio III, relato 7)

"Para mim, as maiores dificuldades foram a entrega dos conteúdos de maneira que eles pudessem de fato entender, interação e a tentativa de manter rapport que eu havia construído com os meus alunos.” (Estágio IV, relato 8)

Fonte: Acervo das autoras (2020).

Um ponto em que os dois relatos convergem é na necessidade de uma interação eficaz nas aulas online. Com a mudança repentina de ambiente, as necessidades interacionais parecem ter sido transferidas para o virtual. Sentimos a necessidade de proximidade; consequentemente, é natural que envidemos esforços para compensar "a falta de interação", como bem ilustra um dos relatos constantes do corpus:

Tem sido bem difícil ficar longe dos alunos e sinto que isso limita bastante a infinidade de coisas que a sala de aula (espaço físico) pode proporcionar. Embora os esforços para minimizar essas limitações sejam diários, sinto que falta ainda aquele "feeling" de você estar em uma sala de aula, de ter pessoas ao seu lado, de ver essas pessoas frente a frente. (Estágio IV, relato 1)

Cada interação é particular ao seu meio; dessa forma, precisamos reconhecer suas particularidades. Com o processo de interação virtual ainda em fase de adaptação, ouvem-se muitas queixas quanto à participação dos alunos durante as aulas. Muitos não ligam seus microfones nem suas câmeras, o que não deixa de ser inquietante, causando a sensação de solidão, de falar para ninguém ou para a tela, afinal de contas passamos, do dia para a noite, da condição de olhar para todos a não olhar para ninguém.

Em consequência da mudança repentina, nota-se, neste período de adaptação, certa hesitação em "abrir a porta de casa" para tantas pessoas com as quais não se costuma conviver intimamente. Em muitos momentos, ambientes utilizados para a aprendizagem não são propícios para ligar o microfone (obras na vizinhança, movimento e barulho em casa, entre outras situações). Há alunos desenvolvendo ansiedade ao ligar o microfone 
ou câmera, muitas vezes por medo de algo dar errado e afetar sua imagem. Coscarelli (2020, p. 17) pondera a questão da interação, sob o ponto de vista do aluno:

[...] fico pensando nos(as) alunos(nas). Cada professor dando aula em uma plataforma ou aplicativo, usando programas e estratégias diferentes, e o(a) aluno(a) tendo de aprender a lidar com vários AVAS e várias ferramentas ao mesmo tempo. Me pergunto se todos têm tranquilidade em casa para estudar, se todos têm acesso rápido e estável à internet.

Kohnke e Jarvis (2020) afirmam que a presença é fundamental para a criação de um ambiente de aprendizagem positivo no ensino remoto e que a simplificação do ensino on-line pode fazer com que os alunos se sintam menos isolados no ambiente virtual. Os autores apresentam estratégias para estabelecer presença, como olhar diretamente para a câmera e não para a tela, a criação de fóruns para que os alunos possam se conhecer melhor, aplicativos como o Mentimeter, Miro ou Mural para uma aprendizagem colaborativa, o uso de emojis nos chats ${ }^{4}$, trazer convidados para entrevistas (pais, alunos de outras turmas, colegas etc.).

O estabelecimento de rapport é um ponto importante a ser considerado por ter relação direta com a mediação no processo de ensino-aprendizagem. Turmas em que não se observa um bom rapport entre alunos e professores, observa-se também uma menor motivação para a aprendizagem. Parece haver um senso comum de que o professor é por natureza extrovertido, sociável, adaptável, mas alguns estudos (COLLINS, 2020; CHINTALAPALLI; TEWARI, 2020) mostram que não é bem assim. Como não são inatas as habilidades relacionais, o docente pode procurar desenvolvê-las.

Personalidade, cuidado e empatia se apresentam como fatores importantes na construção de rapport. Ainda nesta perspectiva, Collins (2020) discute algumas questões como o reconhecimento do outro como indivíduo, suporte e monitoramento, disponibilidade, acessibilidade e responsividade para tal construção.

As questões de reconhecimento do outro como indivíduo e responsividade devem ser consideradas de acordo com o contexto cultural em que se encontram professor e alunos. Traçar perfis individuais (aluno) e coletivos (turma) pode ser uma boa estratégia. Uma forma eficiente de fazê-lo é a utilização de fóruns em que professor e alunos falem sobre si mesmos, suas preferências, personalidades, pontos de vista. Uma vez que é dependente de seu contexto cultural, a responsividade precisa ser fomentada. Assim

\footnotetext{
${ }^{4}$ Os autores sugerem que, ao cumprimentar os alunos, o professor pergunte como todos estão se sentindo e que respondam no chat utilizando emojis.
} 
sendo, seria interessante solicitar que os alunos respondessem a posts de pelo menos mais três alunos (KOHNKE; JARVIS, 2020).

\section{Necessidade de dinamismo nas aulas (de educação infantil)}

Quadro 5: Excerto de relatos dos participantes.

\footnotetext{
"Tivemos (e ainda temos) que nos reinventar, buscar formas de chamar a atenção das crianças para nossas aulas" (Estágio III, relato 7)

"Nas aulas do infantil, precisa cantar e fazer o máximo para que aquela aula remota chegue o mais próximo possível de uma aula presencial.” (Estágio III, relato 12)

"Meu obstáculo mais forte foi 'Como ensinar de forma lúdica para crianças de forma remota?' e logo após veio ‘Como atraí-los? Como manter o ambiente de aprendizado interessante e acessível a todos?' Inicialmente, senti muita insegurança e sofri muito por isso. Sofri mais ainda por estar sendo 'vigiada' pelos pais. Então, diariamente havia um peso sobre mim de sempre tentar fazer algo diferente e melhor não só por causa dos meus alunos, mas principalmente porque os pais estavam junto deles.” (Estágio IV, relato 2)
}

Fonte: Acervo das autoras (2020).

Pelos relatos apresentados acima, observamos que a necessidade de dinamismo nas aulas apresenta-se como um desafio de forma ainda mais marcante para os professores da educação infantil. O mesmo nos é mostrado pela pesquisa realizada pelo Instituto Península, já citada anteriormente no presente artigo, a qual revelou que

$88 \%$ dos professores indicaram que nunca tinham dado aula remota antes da pandemia. Ficou evidente que para o nível de ensino de educação infantil e creche, a vulnerabilidade é maior: as aulas online precisam de ter cuidadores experientes para lidar e potenciar a riqueza da primeira infância in situ [...] (INSTITUTO PENÍNSULA, 2020)

A saída do ambiente da sala de aula, totalmente voltado para essa atividade, e o fato de os alunos estarem em casa, muitas vezes em seus próprios quartos ou na sala "disputando" espaço com outras atividades domésticas e dependendo da conexão com a internet, pode gerar distração e tempo de concentração reduzido, especialmente em relação às crianças. Consequentemente, muitos professores se deparam com a questão delicada de manter suas aulas tão dinâmicas quanto poderiam ser as aulas presenciais, o que gera angústia e insegurança. Para Junqueira (2020, p. 34), 
Professores(as), muitos(as) sem experiência prévia e carentes de apoio técnico e material, buscaram ensinar conteúdos curriculares através da internet simulando o que fazem em suas salas de aula, por vezes demonstrando criatividade para usos não prescritos das tecnologias digitais, a fim de ensinar conceitos complexos aos(às) alunos(as). Se as práticas conteudistas (unidirecionais, massivas e maçantes) já enfrentam limites na escola tradicional, sendo fruto de desinteresse e limitada participação dos(as) alunos(as), na internet se mostraram ainda mais problemáticas, pois contrastam com a natureza interativa, dinâmica e fluida das tecnologias de comunicação em rede. Ou seja, a sala de aula tradicional, focada no ensino de conteúdos e pouco interativa, se deslocou para as redes e gerou desinteresse dos(as) alunos(as) uma vez passada a fase inicial da curiosidade diante da novidade.

O desafio é enorme e desgastante, uma vez que observamos apenas uma transferência de meios, sem qualquer preparação prévia; afinal, como afirma Ribeiro (2020, p. 116), “[...] Ninguém sabe como proceder. E isso por uma razão muito simples: nenhum(a) de nós passou por isso antes." Na busca de solucionar tal questão, Junqueira (2020, p. 37) nos apresenta o conectivismo, perspectiva teórica que surgiu no Canadá e

se baseia no desenvolvimento de habilidades dos(as) alunos(as) para explorar o vasto repositório de informações das redes, identificar critérios de relevância dessas informações (particularmente quanto à sua correção, expressão de diversas perspectivas e atualidade) e colaborar com redes de informação e usuários na criação de novas conexões e novos conhecimentos a partir das múltiplas interações.

A proposta se fundamenta na ideia de trabalhar a autonomia dos alunos, a qual não é uma novidade se pensarmos no que dizia Paulo Freire (2003, p. 47): “[...] ensinar não é transferir conhecimento, mas criar as possibilidades para sua própria produção ou a sua construção". Apesar de não ser uma ideia nova, talvez essa nova realidade trazida pela pandemia tenha vindo para nos lançar de forma mais concreta nessa busca.

Há o fato de que o próprio ambiente virtual estimula a dispersão. Segundo Paiva (2020, p.58), "muitas são as oportunidades de navegação e de interação, e isso pode acabar nos distraindo do objetivo daquele momento". Com as crianças, o uso de atividades lúdicas é uma boa estratégia para melhorar a concentração durante as atividades on-line. Versões digitais de jogos tradicionais e aplicativos, como "Onde Está Wally?", jogo da memória, jogo dos 7 erros, "Fui ao mercado", exercitam a memória, treinam a concentração e dinamizam as aulas online. 
Tais propostas apresentadas brevemente estão embasadas, como dito anteriormente, na busca de se trabalhar com a autonomia e a liberdade do aluno, de torná-lo protagonista de sua aprendizagem. Para tanto, é interessante se pensar as aulas e as atividades centradas na participação dos discentes e se utilizar de todas as vantagens que a tecnologia traz consigo (CECÍLIO, 2020).

\section{Esgotamento}

Quadro 6: Excerto de relatos dos participantes.

"Antes das aulas precisavam ser feitos Tds e slides, então tomava muito tempo para isso, e acabava sendo um trabalho estressante.” (Estágio III, relato 12)

“(...) ensino remoto nos obriga o uso constante de computadores e outros aparelhos o que pode causar lesões por esforço repetitivo como tendinites; outro ponto seria a dificuldade de separar a vida pessoal das aulas porque você acaba tendo que fornecer seu telefone pessoal para ficar constantemente em contato com os alunos, núcleos gestores, enfim, seu expediente não teria fim." (Estágio IV, relato 6)

Fonte: Acervo das autoras (2020).

Os excertos citados acima abordam a questão do desgaste, queixa frequente e preocupante relatada por muitos professores em sua atividade de forma remota. Bertacco (2020, p. 16), em relato publicado no periódico Modern English Teacher, afirma ser real a fadiga durante o ensino remoto emergencial. Para a autora, o estresse imposto às cordas vocais e a energia exigida somadas à falta de limites entre o lar e o ambiente de trabalho são esgotadores. A adaptação é delicada. Por não haver experimentado nada semelhante anteriormente, é natural a insegurança sobre como proceder.

Para Rojo (2020, p. 41),

Do lado do professor, pesa contra o uso de seus próprios equipamentos e conexão, em geral sem nenhum amparo financeiro da instituição para a qual trabalha, e a exigência de maior tempo de preparação mesmo se mantendo o número de aulas.

A mudança para o meio digital exige interações e letramentos diferentes, o que requer, consequentemente, um esforço maior por parte do professor, acrescido ao trabalho já multifuncional e complexo da atividade professoral. Ribeiro (2020 p.116) traz 
um meme em que uma professora lastima: "Saudade de ser professora... agora tenho que ser youtubber, influencer, cameraman, redatora...”. Segundo a autora “(...) não estamos preparados, mas isso vinha antes do vírus" (ibid.).

Se por um lado o professor tem atividades em excesso, por outro, o movimento físico é reduzido, o que é prejudicial à saúde. Nathaliia Anisova (2016), professora de francês a distância, explicou em um artigo que escreveu para a revista Le français dans le monde, $\mathrm{n}^{\mathrm{o}} 406$, na edição de julho e agosto de 2016, dois pontos que ela considera inconvenientes desse tipo de trabalho e o que ela faz para superá-los. O primeiro ponto é o fato de ficar muito tempo sentada na mesma posição, a autora relata praticar exercícios físicos e diz não ser um capricho de sua parte, mas uma necessidade, pois garante sua saúde física. A segunda questão apontada por ela está em saber organizar seu tempo, pois, já que ela trabalha em casa, há sempre atividades domésticas a serem resolvidas também, e é preciso organização. Como solução para isso, ela indica que procura sempre planejar cuidadosamente o seu dia.

Suporte, monitoramento e disponibilidade, se não planejados e bem estruturados, podem agravar o esgotamento docente, já observado neste período. Parece haver uma noção de que por estar em casa, o professor tem todo o tempo disponível para atendimento. Sabemos que não é bem assim. A docência é uma profissão como qualquer outra, com o agravante de se levar trabalho para casa (planejamento, correção de provas, orientação, etc.). Segundo Amigues (2004, p. 49),

[...] o esgotamento do professor também está ligado à especificidade de sua atividade: o professor é, ao mesmo tempo, um profissional que prescreve tarefas dirigidas aos alunos e a ele mesmo; um organizador do trabalho dos alunos, que ele deve regular ao mesmo tempo em que os mobiliza coletivamente para a própria organização da tarefa; um planejador, que deve reconceber as situações futuras em função da ação conjunta conduzida por ele e por seus alunos, em função dos avanços realizados e das prescrições.

Como todo trabalhador, o professor precisa de descanso. Por esse motivo, o estabelecimento de tempo para atendimento aos alunos (virtual office hours) é uma estratégia a ser considerada (KOHNKE; JARVIS, 2020). Outras alternativas a se considerar seriam a utilização de contas comerciais de aplicativos de mensagens, como o WhatssApp, e agendamento prévio para atendimento por videoconferência. Estabelecer limites para as horas de trabalho é fundamental para evitar o esgotamento, evidenciado nas horas extras de planejamento e produção/adaptação de conteúdo para tornar as atividades virtuais minimamente dinâmicas. 
O estabelecimento de um cronograma cuidadosamente planejado e devidamente cumprido por alunos, professores e gestão, respeitadas as horas contratadas, pode ser uma estratégia eficaz para reduzir o esgotamento. Não sugerimos com isso que tarefas entregues fora do prazo não sejam recebidas, mas que os envolvidos no processo sejam conscientizados de que o feedback àquela atividade entregue com atraso também sofrerá atraso em sua devolução, uma vez que precisará ser reajustada ao cronograma.

A comunicação assíncrona também necessita de cautela. Ouvimos queixas frequentes de atividades sendo prescritas e enviadas em pleno domingo, com o agravante de imposição de prazos curtíssimos para sua realização. E-mails e mensagens podem até ser enviados em horário conveniente para o remetente, desde que o mesmo aguarde a resposta dentro do prazo usual, a contar de quando se inicia o horário da atividade contratada.

\section{CONSIDERAÇÕES FINAIS}

Ensinar e aprender são atividades que se conectam e se completam. Não há uma sem a outra. Fazem parte de um ciclo que não se encerra, uma vez que estamos constantemente aprendendo e ensinando. Como se tratam de atividades diretamente relacionadas, mudanças na forma de aprender provocam mudanças na forma de ensinar. Não nascemos prontos. Somos indivíduos que fazem parte de um coletivo em constante aprendizagem. Além dos saberes científicos e pedagógicos (ANASTASIOU, 2002), acumulamos saberes a partir de vivências, do olhar do outro e para o outro - por vezes representado por nós mesmos (BAKHTIN, 2000, 2018) - sobre a atividade docente.

Como afirmamos na introdução, não é nossa intenção esgotar o assunto aqui, pelo contrário, propomos a discussão constante entre todos aqueles que fazem parte do processo de ensino e aprendizagem. A atividade do professor é, por vezes, uma atividade solitária, e nós acreditamos ser fundamental a troca de vivências e conhecimentos para que seja possível um maior desenvolvimento, não só do indivíduo, mas de todo o coletivo do qual ele participa, tornando, assim, mais fácil encontrarmos saídas para momentos desafiadores como este.

A pandemia nos apresentou uma realidade nunca antes imaginada, e não podemos achar que, com o fim dela, tudo voltará a ser como era antes. Precisamos seguir em frente no processo agora iniciado; assim como jamais seremos os mesmos, nossa forma de ensinar e aprender também não mais será. Não precisamos desaprender o que sabemos, mas somos chamados a construir um novo ambiente educacional, no qual sejamos capazes de aliar o nosso conhecimento presente ao futuro que tantas vezes resistimos em abraçar. 


\section{REFERÊNCIAS}

ALMEIDA, M. E. B. de. Transformações no trabalho e na formação docente na educação a distância on-line. Em Aberto, v. 23, n. 84, p. 67-77, 2010.

AMIGUES, R. Trabalho do professor e trabalho de ensino. In: MACHADO, A. R. (org.). O ensino como trabalho: uma abordagem discursiva. Londrina: Eduel, 2004. p. 35-54.

ANASTASIOU, L. das G. C. A docência como profissão do ensino superior e os saberes pedagógicos e científicos. Revista Univille, Joinville, v.7, n.1, p. 7-16, 2002.

ANISOVA, N. "Enseigner à des étudiants de differénts continents". Le français dans le monde. Paris, n. 406, p. 56-57, juillet-août 2016.

ARAÚJO, A. de A. C. O trabalho docente no ensino de língua inglesa sob o olhar do formador e do formando: análise das relações dialógicas na atividade linguageira através do Quadro Teórico-Metodológico da Autoconfrontação. 2018. 743 f. Tese (Doutorado Acadêmico em Linguística Aplicada) - Programa de Pós-Graduação em Linguística Aplicada, Universidade Estadual do Ceará, Fortaleza, 2018. Disponível em: http://www. uece.br/posla/download/teses/. Acesso em: 18 mar. 2020.

BAKHTIN, M. Estética da criação verbal. 3 ed. Trad. Maria Ermantina Galvão. São Paulo: Martins Fontes, 2000.

BAKHTIN, M. Problemas da poética de Dostoiévski. 5 ed. Trad. Paulo Bezerra. Rio de Janeiro: Forense Universitária, 2018.

BERTACCO, L. The four commonplaces: teaching and learning in the time of COVID. Modern English Teacher, v. 29, p. 16-21, issue 3, Jul. 2020.

BRANDÃO, G. R. Olhares e fazeres distintos sobre a intervenção e a pesquisa. In: BANKS-LEITE, L.; SMOLKA, A. L. B.; ANJOS, D. D. dos. Diálogos na perspectiva histórico-cultural: interlocuções com a clínica da atividade. Campinas: Mercado das Letras, 2016. p. 131-152.

BUNZEN, C. O ensino de língua materna em tempos de pandemia. In: RIBEIRO, A. E.; VECCHIO, P. de M. (orgs.). Tecnologias digitais e escola: reflexões no projeto aula aberta durante a pandemia. São Paulo: Parábola, 2020. p. 21-30.

CECÍLIO, C. Ensino remoto: como reinventar sua aula com PPT e Google Slides. Revista Nova Escola. 29 jun. 2020. Disponível em: https://novaescola.org.br/ conteudo/19403/ensino-remoto-como-reinventar-sua-aula-com-ppt-e-googleslides. Acesso em: 17 dez. 2020. 
CHINTALAPALLI, V.; TEWARI, S. Proxemics and pandemics. Modern English Teacher, v. 29, issue 3, p. 22-24, Jul. 2020.

COLLINS, V. Building rapport with your online community of learners. Modern English Teacher, v. 29, issue 4, p. 25-27, Oct. 2020.

COSCARELLI, C. V. Ensino de língua: surtos durante a pandemia. In: RIBEIRO, A. E.; VECCHIO, P. de M. (orgs.). Tecnologias digitais e escola: reflexões no projeto aula aberta durante a pandemia. São Paulo: Parábola, 2020. p. 15-20.

FREIRE, P. Pedagogia da autonomia: saberes necessários à prática educativa. São Paulo: Paz e Terra, 2003.

FREITAS, M. T. Letramento e formação de professores. Educação em Revista, Belo Horizonte, v. 26, n. 03, p. 335-352, 2010.

GIMENEZ, T. Desafios contemporâneos na formação de professores de línguas: contribuições da Linguística Aplicada. In: FREIRE, M. M.; ABRAHÃO, M. H. V.; BARCELOS, A. M. F. Linguística Aplicada e contemporaneidade. Campinas: Pontes Editores, 2005. p. 183-201.

GIMENEZ, T. Narrativa 14: permanências e rupturas no ensino de inglês em contexto brasileiro. In: LIMA, D. C. de (org.). Inglês em escolas públicas não funciona? Uma questão, múltiplos olhares. São Paulo: Parábola Editorial, 2018. p. 47-54.

GATTI. B. A. et al. Professores do Brasil: novos cenários de formação. Brasília: Unesco, 2019.

INSTITUTO PENÍNSULA. Sentimento e percepção dos professores brasileiros nos diferentes estágios do coronavírus no Brasil. São Paulo. 2020. Disponível em: https:// www.institutopeninsula.org.br/pesquisa-sentimento-e-percepcao-dos-professores-nosdiferentes-estagios-do-coronavirus-no-brasil/. Acesso em: 30 nov. 2020.

JESUS, D. M. Reculturação, reestruturação e reorganização temporal de professores no ambiente digital. 2007. Tese (Doutorado em Linguística Aplicada e Estudos da Linguagem) - Pontifícia Universidade Católica de São Paulo (PUC-SP), 2007. Disponível em: http:// www.dominiopublico.gov.br/download/ texto/cp039084.pdf. Acesso em: 02 dez. 2020.

JUNQUEIRA, E. S. A EaD, os desafios da educação híbrida e o futuro da educação. In: RIBEIRO, A. E.; VECCHIO, P. de M. (orgs.). Tecnologias digitais e escola: reflexões no projeto aula aberta durante a pandemia. São Paulo: Parábola, 2020. p. 31-39. 
KOHNKE, L.; JARVIS, A. Keeping the ball rolling. Modern English Teacher, v. 29, issue 3, p. 25-26, Jul. 2020.

LACERDA, C. R. Saberes necessários à prática docente no ensino superior: olhares dos professores do curso de bacharelado. Revista Docência do Ensino Superior, v. 5, n. 2, p. 79-100, out. 2005.

MAGALHÃES, M. C. A linguagem na formação de professores como profissionais reflexivos e críticos. In: MAGALHÃES, M. C. (org.). A formação do professor como um profissional crítico. Campinas: Mercado de Letras, 2004. p. 81-104.

MORAES, R. M. A.; LOPES, W. B. Instrumentos mediadores na atividade linguageira de professores iniciantes de francês. Estudos da Lingua(gem), v. 17, p. 117-132, jul./set. 2019. Disponível em: https://periodicos2.uesb.br/index.php/estudosdalinguagem/article/ view/5943/4462. Acesso em: 01 dez. 2020.

MORAES, R. M. A.; MAGALHÃES, E. M. Abordagem clínica na análise da atividade docente: uma via unindo pesquisa, intervenção e formação. Horizontes, v. 35, n. 3, p. 105 120, 29 dez. 2017. Disponível em: https://revistahorizontes.usf.edu.br/horizontes/article/ view/515/256. Acesso em: 01 dez. 2020.

PAIVA, V. L. M. O. Tecnologia durante o confinamento. In: RIBEIRO, A. E.; VECCHIO, P. de M. (orgs.). Tecnologias digitais e escola: reflexões no projeto aula aberta durante a pandemia. São Paulo: Parábola, 2020. p. 57-69.

RIBEIRO, A. E. Tudo o que fingimos (não) saber sobre tecnologias e educação. In: RIBEIRO, A. E.; VECCHIO, P. de M. (orgs.). Tecnologias Digitais e Escola: reflexões no projeto aula aberta durante a pandemia. São Paulo: Parábola Editorial, 2020. p. 111-117.

ROJO, R. (Re)pensar os multiletramentos na pandemia. In: RIBEIRO, A. E.; VECCHIO, P. de M. (orgs.). Tecnologias Digitais e Escola: reflexões no projeto aula aberta durante a pandemia. São Paulo: Parábola Editorial, 2020. p. 40-43.

TRAN, T. Online or not online: that's not the question. Modern English Teacher, v. 29, issue 4, p. 10-12, Oct. 2020. 


\section{ANEXOS}

Figura 1: Início do questionário Estágio III: autorização.

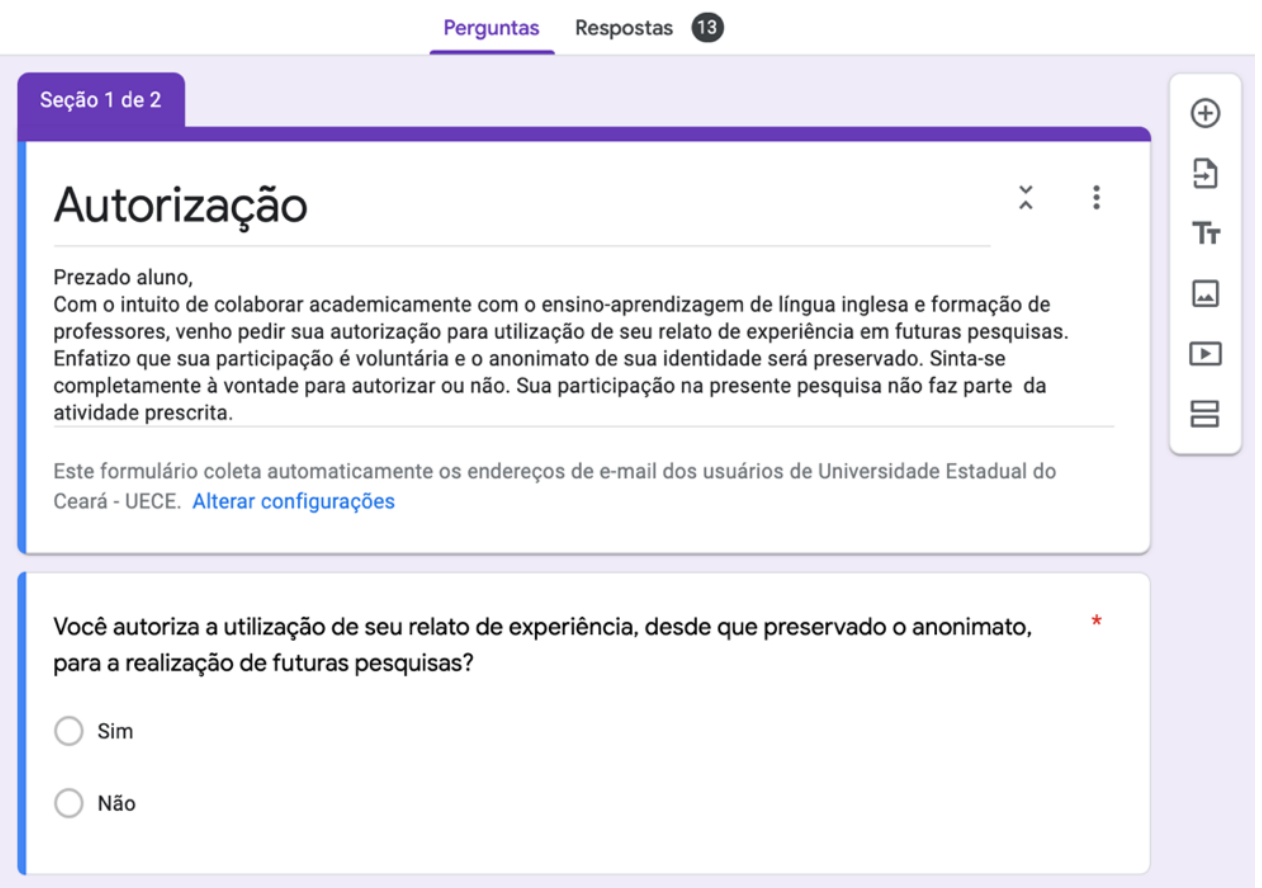

Fonte: Formulário produzido pelas autoras - acervo próprio (2020). 
Figura 2: Início do questionário Estágio IV: autorização.

:E Relato de experiência Estágio IV 㫨

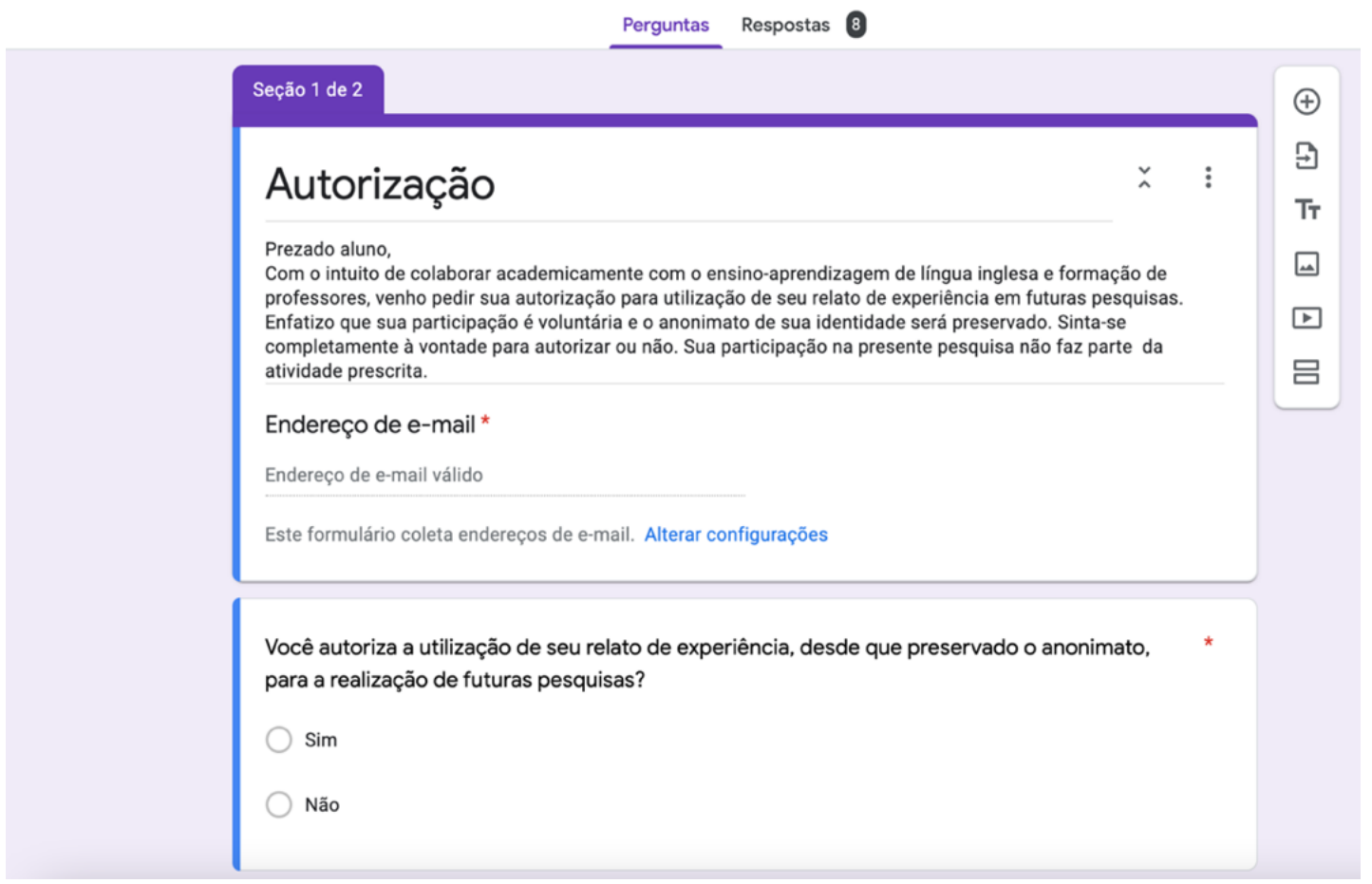

Fonte: Formulário produzido pelas autoras - acervo próprio (2020).

Recebido em: 22 fev. 2021.

Aceito em: 29 mar. 2021. 